\title{
Pancreas sparing duodenectomy versus pancreaticodudoenectomy for duodenal carcinoma: a comparison study
}

\author{
Maheswaran Pitchaimuthu*, Mohammad S. Khan, S. Pearson, Chris Coldham, James Hodson, \\ Ravi Marudanayagam, John K Roberts, Paolo Muiesan, John Isaac, \\ Darius F. Mirza, Robert P. Sutcliffe
}

The Liver and HPB Unit, Queen Elizabeth Hospital, Birmingham, United Kingdom

Received: 04 May 2016

Accepted: 11 May 2016

\section{*Correspondence:}

Dr Maheswaran Pitchaimuthu,

E-mail: drmpitchaimuthu@yahoo.com

Copyright: () the author(s), publisher and licensee Medip Academy. This is an open-access article distributed under the terms of the Creative Commons Attribution Non-Commercial License, which permits unrestricted non-commercial use, distribution, and reproduction in any medium, provided the original work is properly cited.

\section{ABSTRACT}

Background: Pancreas-sparing duodenectomy (PSD) may be an alternative to pancreaticoduodenectomy (PD) for duodenal cancers located distant from the ampulla. PSD avoids the potential complications of a pancreaticoenteric anastomosis, but the long-term outcomes are unknown.

Methods: Patients who underwent surgical resection of duodenal cancer were identified from a prospectively maintained database. Clinical and pathological data were collected, and long-term cancer-related outcomes were analyzed.

Results: 19 patients underwent PSD and 60 PD between January 1993 and March 2014. Morbidity (p=0.196), 90-day mortality $(\mathrm{p}=0.379)$ and length of stay $(\mathrm{p}=0.137)$ were similar in both groups. However, there were more anastomotic leaks in the PD group (33\% versus. 5\%; $\mathrm{p}=0.017)$. Lymph node yield $(\mathrm{p}<0.001)$ was significantly lower after PSD. There was no significant difference in five-year overall $(\mathrm{p}=0.943)$, disease-specific $(\mathrm{p}=0.781)$ or recurrence-free $(\mathrm{p}=0.695)$ survival rates. No significant difference in the lymph node ratio (LNR) between the groups.

Conclusions: PSD avoids the risks of a pancreatic anastomosis associated with PD. Despite a significantly lower lymph node harvest, similar survival outcomes can be achieved with PSD in patients with duodenal carcinoma not involving $\mathrm{D}_{2}$.

Keywords: Pancreas sparing duodenectomy (PSD), Pancreatico duodenectomy (PD), Lymph node yield, Lymph node ratio (LNR), Survival

\section{INTRODUCTION}

Adenocarcinoma is the commonest neoplasm affecting the duodenum. ${ }^{1,2}$ However; duodenal adenocarcinoma is rare and accounts for only $0.3 \%$ of all gastrointestinal malignancies. ${ }^{3,4}$ Surgical resection is the only potentially curative option in patients with localized disease, and pancreatico-duodenectomy (PD) is the procedure of choice for periampullary tumours, but is associated with significant morbidity and mortality. ${ }^{5}$ For tumours distant from the ampulla, pancreas sparing partial duodenectomy (PSD) may be an alternative approach and has been advocated due to potentially lower morbidity than PD. ${ }^{6}$
While PSD provides adequate tumour clearance, but avoids extensive dissection, which may affect adequate lymph node clearance. ${ }^{6}$ But some authors reported similar lymph node clearance with both PSD and PD for distal duodenal tumours and less lymph node clearance with PSD than PD for proximal duodenal tumours. ${ }^{7}$

However, due to the relative rarity of duodenal adenocarcinoma, the available data concerning the outcomes after surgical resection are limited to case series, and there are very few reports comparing the longterm outcomes after PSD and PD. ${ }^{7}$ 
The primary aim of this study was to compare whether pancreas sparing duodenectomy is a safer alternative and oncologically acceptable option for duodena cancers away from the ampulla when compared to standard pancreaticoduodenectomy in a consecutive series from a single centre. The secondary aim was to evaluate the impact of pathological variables, including lymph node yield and ratio on long-term survival.

\section{METHODS}

This was a retrospective analysis of a prospectively maintained institutional database. After institutional audit committee approval, all consecutive patients who underwent surgical resection of duodenal adenocarcinoma were identified over a period of 21 years (January 1993 to March 2014) and were selected for review. In our unit, the decision to perform pancreassparing duodenectomy instead of pancreaticoduodenectomy has been made intraoperatively by the operating surgeon, and was considered in patients with lesions distant from the ampulla when macroscopic tumour clearance was deemed possible. However, this was discussed in a multi-disciplinary meeting preoperatively with available imaging. Patients who had PSD were compared with patients who underwent PD who served as a control group. Patients' demographic details, co-morbidities, clinical presentation, part of the duodenum involved and the nature of surgery were collected.

\section{Surgical technique}

Following abdominal exploration, the hepatic flexure of the colon was retracted inferiorly and an extensive Kocher maneuver was performed, elevating the duodenum out of the retroperitoneum. Next, the attachments at the ligament of treitz were divided, and the mesentery of the proximal jejunum was ligated and divided. The jejunum was then divided distal to the ligament of treitz, and the duodenojejunal specimen was passed beneath the superior mesenteric vessels to the right upper quadrant. The resection included the distal second portion of the duodenum as well as the third and fourth portions of the duodenum, as clinically indicated. At the proximal extent of the resection, the duodenum was divided. In most cases, the retained distal jejunum was delivered through a rent in the right transverse mesocolon, and a retrocolic duodenojejunostomy was performed in two layers. The duodenojejunostomy was often performed in end-to-side fashion, although other anatomic arrangements have been used (Figure 1).

A nasojejunal tube was placed distal to the anastomosis for postoperative feeding, if required and a tube drain was placed adjacent to the anastomosis. For proximal lesions after kocherisation the first and proximal second portions are removed along with distal stomach. Intestinal continuity was achieved with standard or Roux Y gastrojejunostomy (Figure 2). Pancreatico-duodenectomy was performed as described elsewhere in the literature either classical or PPPD. All patients received standard postoperative care and lately ERAS protocol was introduced in our unit.

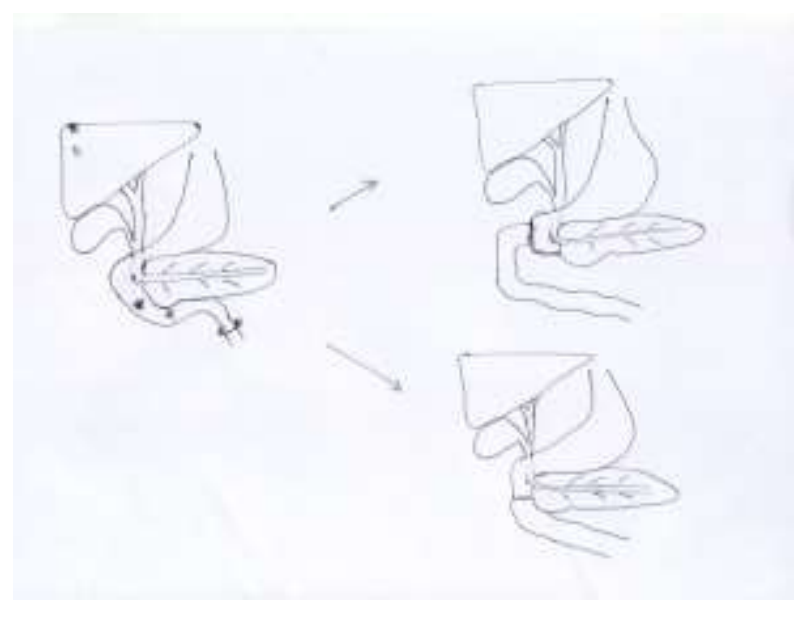

Figure 1: Pancreas sparing distal duodenectomy: showing possible reconstruction after distal duodenal lesion (marked with*) resection.

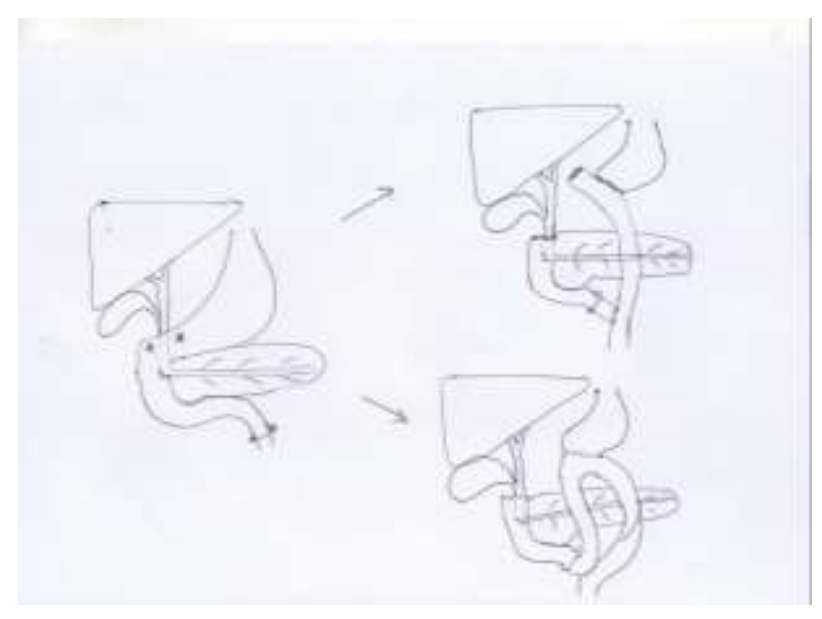

Figure 2: Pancreas sparing proximal duodenectomy: showing possible reconstruction after proximal duodenal lesion (marked with*) resection.

\section{Postoperative outcome}

Postoperative complications were recorded according to Clavien-Dindo classification, and 90-day mortality was recorded. ${ }^{8}$ Histological data were collated regarding tumour size, resection margin, number of lymph nodes involved and number of positive lymph nodes. Lymph node ratio (LNR) was calculated by dividing the total number of positive nodes by total number of lymph nodes harvested and survival with LNR of more than 0.2 and 0.3 were analyzed. Eligible patients received $5 \mathrm{FU}$ based adjuvant treatment and details regarding postoperative chemotherapy and tumour recurrence were collected. Overall, disease free and disease specific survival was calculated for each group. If there were no follow up details available in our hospital system, then patients' 
general practitioners were contacted and last available follow up details were gathered.

\section{Statistical methods}

Continuous variables were compared between the two types of surgery using Mann-Whitney tests. Categorical variables were compared using Fisher's exact tests, with Kendall's Tau used where the categories were ordinal. Survival outcomes were assessed using Kaplan-Meier curves, with log-rank tests for comparisons between groups. Missing data were excluded on an analysis-byanalysis basis. All analyses were performed using IBM SPSS Statistics 22 (IBM Corp. Armonk, NY), with $\mathrm{p}<0.05$ considered to be statistically significant.

\section{RESULTS}

Data were available for 79 patients, with a median age of 66 years (range: 26-86, quartiles: 55-71), of whom 43 (54\%) were male. 19 (24\%) underwent pancreas sparing duodenectomy (PSD) and 60 patients (76\%) underwent pancreatico-duodenectomy (PD).

Table 1: Demographics and clinical presentation.

\begin{tabular}{|c|c|c|c|}
\hline & $\mathrm{PD}(\mathrm{N}=60)$ & PSD $(\mathrm{N}=19)$ & p-value \\
\hline \multicolumn{4}{|l|}{ Demographics } \\
\hline $\begin{array}{l}\text { Age at surgery } \\
\text { (years) }\end{array}$ & $65(55-71)$ & $66(49-75)$ & 0.891 \\
\hline Gender (Male) & $33 / 60(55 \%)$ & $10 / 19(53 \%)$ & 1.000 \\
\hline \multicolumn{4}{|l|}{ Symptoms } \\
\hline Pain & $21 / 59(36 \%)$ & $4 / 18(25 \%)$ & 0.393 \\
\hline Jaundice & $13 / 59(22 \%)$ & $0 / 18(0 \%)$ & 0.031 \\
\hline Vomiting & $17 / 59(29 \%)$ & $10 / 18(56 \%)$ & 0.050 \\
\hline Weight loss & $22 / 59(37 \%)$ & $10 / 18(56 \%)$ & 0.185 \\
\hline $\begin{array}{l}\text { GI bleeding } \\
\text { /Anaemia }\end{array}$ & $17 / 59(29 \%)$ & $5 / 18(28 \%)$ & 1.000 \\
\hline \multicolumn{4}{|c|}{ Tumour location } \\
\hline $\begin{array}{l}\text { Part of } \\
\text { duodenum } \\
\text { involved }\end{array}$ & & & $<0.001$ \\
\hline Dl & $4 / 60(6.5 \%)$ & $2 / 18(11 \%)$ & \\
\hline D2 & $51 / 60(85 \%)$ & $1 / 18(6 \%)$ & \\
\hline D3 & $4 / 60(6.5 \%)$ & $\begin{array}{l}10 / 18 \\
(56 \%)\end{array}$ & \\
\hline D4 & $1 / 60(2 \%)$ & $5 / 18(28 \%)$ & \\
\hline
\end{tabular}

Categorical data reported as: "n/N (\%)", with p-values from Fisher's exact tests, and continuous data reported as: "median (quartiles)", with p-values from Mann-Whitney tests, unless stated otherwise. K p-value from Kendall's Tau.

Patient demographics were similar between groups (Table 1). 55/60 patients $(91 \%)$ in the PD group had proximal (first and second part) duodenal lesions compared to only $3 / 19$ patients $(17 \%)$ in the PSD group $(\mathrm{p}<0.001)$. As expected, jaundice was more common in patients who underwent PD $(22 \%$ vs. $0 \%, \mathrm{p}=0.031)$ and
PSD patients more likely to present with vomiting (56\% vs. $29 \%, \mathrm{p}=0.050$ ).

Table 2: Histological outcome.

\begin{tabular}{|c|c|c|c|}
\hline & $\begin{array}{l}\text { PD } \\
(\mathbf{N}=60)\end{array}$ & $\begin{array}{l}\text { PSD } \\
(\mathbf{N}=19)\end{array}$ & $\begin{array}{l}\text { p- } \\
\text { Value }\end{array}$ \\
\hline $\begin{array}{l}\text { Tumour size } \\
\text { (in } \mathrm{cms} \text { ) }\end{array}$ & $4(3-6)$ & $4(4-6)$ & 0.933 \\
\hline $\begin{array}{l}\text { Number of } \\
\text { lymph nodes } \\
\text { removed }\end{array}$ & $17(11-24)$ & $6(1-15)$ & $<0.001$ \\
\hline $\begin{array}{l}\text { Number of } \\
\text { lymphnodes } \\
\text { involved }\end{array}$ & $1(0-5)$ & $0(0-2)$ & 0.071 \\
\hline Local invasion & $40 / 53(75 \%)$ & $\begin{array}{l}5 / 16 \\
(31 \%)\end{array}$ & 0.002 \\
\hline $\begin{array}{l}\text { Lymphovascular } \\
\text { invasion }\end{array}$ & $6 / 59(10 \%)$ & $\begin{array}{l}1 / 18 \\
(5 \%)\end{array}$ & 1.000 \\
\hline $\begin{array}{l}\text { Perineural } \\
\text { invasion }\end{array}$ & $11 / 59(19 \%)$ & $\begin{array}{l}0 / 18 \\
(0 \%)\end{array}$ & 0.0582 \\
\hline \multicolumn{4}{|l|}{ Tumour grade } \\
\hline $\begin{array}{l}\text { Moderately } \\
\text { differentiated }\end{array}$ & $59 / 60(98 \%)$ & $\begin{array}{l}17 / 19 \\
(90 \%)\end{array}$ & 0.142 \\
\hline $\begin{array}{l}\text { Poorly } \\
\text { differentiated }\end{array}$ & $1 / 60(2 \%)$ & $\begin{array}{l}2 / 19 \\
(10 \%)\end{array}$ & 0.163 \\
\hline $\begin{array}{l}\text { Resection } \\
\text { margin involved }\end{array}$ & $5 / 59(8 \%)$ & $\begin{array}{l}4 / 18 \\
(22 \%)\end{array}$ & 0.201 \\
\hline \multicolumn{4}{|l|}{ Disease stage } \\
\hline Stage 1 & $7(12 \%)$ & $1(5 \%)$ & \\
\hline Stage 2 & $27(45 \%)$ & $8(42 \%)$ & \\
\hline Stage 3 & $24(40 \%)$ & $10(53 \%)$ & \\
\hline Stage 4 & $2(3 \%)$ & 0 & \\
\hline $\begin{array}{l}\text { Lymph node } \\
\text { involvement }\end{array}$ & $33 / 55(60 \%)$ & $\begin{array}{l}8 / 18 \\
(44 \%)\end{array}$ & 0.283 \\
\hline $\begin{array}{l}\text { Number of } \\
\text { lymph nodes } \\
(>6)\end{array}$ & $50 / 55(91 \%)$ & $\begin{array}{l}7 / 18 \\
(39 \%)\end{array}$ & $<0.001$ \\
\hline $\begin{array}{l}\text { Number of lymph } \\
\text { nodes }(>15)\end{array}$ & $33 / 55(60 \%)$ & $\begin{array}{l}5 / 18 \\
(28 \%)\end{array}$ & 0.028 \\
\hline
\end{tabular}

Histological variables are compared in Table 2. Tumour size $(\mathrm{p}=0.933)$, proportion of patients with lymph node metastases (stage III) $\quad(\mathrm{p}=0.283)$, lymphovascular invasion $(\mathrm{p}=1.000)$, perineural invasion $(\mathrm{p}=0.0582)$ and tumour grade were similar in both groups. 54 patients (92\%) in the PD group and 14 patients $(78 \%)$ in the PSD group underwent an R0 resection $(\mathrm{p}=0.201)$. However, the median lymph node yield was significantly lower in the PSD group (6 vs. 17, $\mathrm{p}=<0.001$ ). At least six lymph nodes were resected in $91 \%$ of PD patients compared to only $39 \%$ of PSD patients $(\mathrm{p}<0.001)$. The lymph node ratio (LNR) was found to be similar in both groups, with medians of 0.10 and 0.05 respectively $(p=0.478)$. This result remained consistent when treating LNR as a dichotomous variable, with no significant difference between the groups in the proportion of patients with LNR $>0.2 \quad(\mathrm{p}=0.554)$ or $>0.3 \quad(\mathrm{p}=1.000)$. Adjuvant 
chemotherapy details were available only for 39 patients, as a significant proportion of our patients receive adjuvant oncological treatment in another hospital.

Since the details on chemotherapy was not available for other patients' survival for patients with and without chemotherapy was not calculated. The overall median follow up period was 21 (IQR 9-54) months.

\section{Short-term outcomes}

Postoperative morbidity was not significantly different between groups $(\mathrm{p}=0.196)$; although anastomotic complications (all 20 leaks in the PD group were pancreatic leaks and 1 patient in the PSD group was duodeno-jejunostomy leak) were more common after PD $(\mathrm{p}=0.017)$ (Table 3). 90-day mortality $(\mathrm{p}=0.379)$ and median length of hospital stay $(\mathrm{p}=0.137)$ were also similar between groups (Table 4).

Table 3: Postoperative complications.

\begin{tabular}{|c|c|c|c|}
\hline Complications & $P D=60$ & $P S D=19$ & p-value* \\
\hline \multicolumn{4}{|l|}{ Surgical } \\
\hline $\begin{array}{l}\text { Anastomotic } \\
\text { leak }\end{array}$ & 20 & 1 & 0.017 \\
\hline Bleeding & 5 & 0 & 0.329 \\
\hline Wound infection & 4 & 3 & 0.350 \\
\hline $\begin{array}{l}\text { Delayed gastric } \\
\text { emptying }\end{array}$ & 3 & 0 & 1.000 \\
\hline Line sepsis & 2 & 2 & 1.000 \\
\hline Chyle leak & 1 & 0 & 1.000 \\
\hline $\begin{array}{l}\text { Wound } \\
\text { dehiscence }\end{array}$ & 1 & 1 & 1.000 \\
\hline SMA thrombosis & 0 & 1 & 1.000 \\
\hline \multicolumn{4}{|l|}{ Medical } \\
\hline Chest infection & 4 & 0 & 0.567 \\
\hline Arrhythmia & 4 & 1 & 1.000 \\
\hline Pleural effusion & 3 & 0 & 1.000 \\
\hline Confusion & 2 & 1 & 0.567 \\
\hline Diabetes & 2 & 0 & 1.000 \\
\hline $\begin{array}{l}\text { Respiratory } \\
\text { failure }\end{array}$ & 2 & 0 & 1.000 \\
\hline $\begin{array}{l}\text { Acute kidney } \\
\text { injury }\end{array}$ & 1 & 0 & 1.000 \\
\hline $\begin{array}{l}\text { Pulmonary } \\
\text { embolism }\end{array}$ & 0 & 1 & 1.000 \\
\hline Urinary retention & 0 & 1 & 1.000 \\
\hline
\end{tabular}

*p-values from Fisher's exact tests.

\begin{tabular}{|c|c|c|c|}
\hline $\begin{array}{l}\text { Postoperative } \\
\text { outcomes }\end{array}$ & PD $(\mathrm{N}=60)$ & PSD (N=19) & p-value \\
\hline $\begin{array}{l}\text { Post-op length } \\
\text { of stay (days) }\end{array}$ & $11(9-15)$ & $10(7-14)$ & 0.137 \\
\hline Complications & $33 / 60(55 \%)$ & $7 / 19(37 \%)$ & 0.196 \\
\hline $\begin{array}{l}\text { Highest } \\
\text { complication } \\
\text { grade }\end{array}$ & & & $0.844^{\mathrm{K}}$ \\
\hline 0 & $27 / 60(45 \%)$ & $12 / 19(63 \%)$ & \\
\hline 1 & $7 / 60(12 \%)$ & $2 / 19(11 \%)$ & \\
\hline 2 & $14 / 60(23 \%)$ & $2 / 19(11 \%)$ & \\
\hline 3 & $3 / 60(5 \%)$ & $2 / 19(11 \%)$ & \\
\hline 4 & $2 / 60(3 \%)$ & $0 / 19(0 \%)$ & \\
\hline $\begin{array}{l}\text { Post-operative } \\
\text { mortality }\end{array}$ & $7 / 60(12 \%)$ & $1 / 19(5 \%)$ & 0.379 \\
\hline $\begin{array}{l}\text { Type of } \\
\text { complication }\end{array}$ & & & 0.686 \\
\hline Medical & $12 / 35(34 \%)$ & $3 / 7(43 \%)$ & \\
\hline Surgical & $23 / 35(66 \%)$ & $4 / 7(57 \%)$ & \\
\hline $\begin{array}{l}\text { Anastomotic } \\
\text { leak* }\end{array}$ & $20 / 60(33 \%)$ & $1 / 19(5 \%)$ & 0.017 \\
\hline \multicolumn{4}{|l|}{ Grade of leak } \\
\hline Grade A & $9 / 20(45 \%)$ & $0 / 1(0 \%)$ & \\
\hline Grade B & $6 / 20(30 \%)$ & $1 / 1(100 \%)$ & \\
\hline Grade C & $5 / 20(25 \%)$ & $0 / 1(0 \%)$ & \\
\hline $\begin{array}{l}\text { Post-operation } \\
\text { chemotherapy } \\
\text { (In patients who } \\
\text { had data } \\
\text { available) }\end{array}$ & $20 / 29(69 \%)$ & $6 / 9(67 \%)$ & 1.000 \\
\hline
\end{tabular}

*All anastomotic leaks in the PD group were related to the pancreatic anastomosis.

\section{Long-term outcomes}

Lymph node involvement was associated with a reduced disease-specific survival (DSS) after PD $(\mathrm{p}=0.018)$, but did not impact on overall (OS) $(\mathrm{p}=0.084)$ or recurrence free (RFS) $(\mathrm{p}=0.194)$ survival. In the PSD group lymph node involvement did not affect these survivals (OS $\mathrm{p}=$ 0.519 , DSS $\mathrm{p}=0.886$, RFS $\mathrm{p}=0.499$ ). Even though the numbers of lymph nodes resected were low in the PSD group, which is statistically significant $(\mathrm{p} \leq 0.001$ for more than 6 and $\mathrm{p}=0.028$ for more than 15 lymph nodes harvested), it did not affect the long-term survival. When compare the lymph node yield and survival $(\leq 6$ and $>6$, $\leq 15$ and $>15$ lymph nodes harvested), the 1,3 and 5 years OS, DSS and RFS were similar between the PSD and PD groups. Higher LNR was associated with significantly shorter overall, disease specific and recurrence free survival in PD patients. The overall long-term survival (overall, disease-specific and recurrence free survivals) were not significantly different between the groups. (Tables 5-8, Figure 3).

Table 4: Post-operative outcome. 
Table 5: Overall survival by factors and surgery type.

\begin{tabular}{|lllll|l|}
\hline & PD $(\mathbf{N}=\mathbf{6 0})$ & & PSD (N=19) & PD vs. PSD \\
p-value
\end{tabular}

OS = Overall Survival. Data reported as Kaplan-Meier estimated rates, with p-values from log-rank tests. $*$ Significant at $\mathrm{p}<0.05$.

Table 6: Disease specific survival by factors and surgery type.

\begin{tabular}{|c|c|c|c|c|c|}
\hline & PD $(\mathbf{N}=60)$ & & PSD $(\mathrm{N}=19)$ & & PD vs. PSD \\
\hline & $1,3,5$ year DSS $(\%)$ & p-value & 1, 3, 5 year DSS (\%) & p-value & p-value \\
\hline Lymph node involved & & $0.018^{*}$ & & 0.886 & \\
\hline No & $94,89,79$ & & $83,67,67$ & & 0.469 \\
\hline Yes & $92,58,45$ & & $100,60,60$ & & 0.496 \\
\hline LNR & & $0.022 *$ & & 0.233 & \\
\hline$\leq 0.2$ & $96,81,69$ & & $86,86,86$ & & 0.622 \\
\hline$>0.2$ & $88,53,40$ & & $100,33,33$ & & 0.778 \\
\hline LNR & & $<0.001 *$ & & 0.061 & \\
\hline$\leq 0.3$ & $97,83,73$ & & $88,88,88$ & & 0.451 \\
\hline$>0.3$ & $82,31,16$ & & $100,0,0$ & & 0.738 \\
\hline Number of lymph nodes & & 0.209 & & 0.308 & \\
\hline$\leq 6$ & $100,33,33$ & & $86,51,51$ & & 0.569 \\
\hline$>6$ & $93,75,62$ & & $100,80,80$ & & 0.491 \\
\hline Number of lymph nodes & & 0.880 & & 0.161 & \\
\hline$\leq 15$ & $100,75,58$ & & $90,51,51$ & & 0.746 \\
\hline$>15$ & $89,69,62$ & & $100,100,100$ & & 0.233 \\
\hline
\end{tabular}

DSS = Disease-Specific Survival. Data reported as Kaplan-Meier estimated rates, with p-values from log-rank tests. *Significant at $\mathrm{p}<0.05$.

Table 7: Recurrence-free survival by factors and surgery type. 


\begin{tabular}{|c|c|c|c|c|c|}
\hline & \multicolumn{2}{|l|}{ PD $(N=60)$} & \multicolumn{2}{|l|}{ PSD (N=19) } & \multirow{2}{*}{$\begin{array}{l}\text { PD vs. PSD } \\
\text { p-value }\end{array}$} \\
\hline & $1,3,5$ year RFS $(\%)$ & p-value & 1, 3, 5year RFS (\%) & p-value & \\
\hline Lymph node involved & & 0.194 & & 0.499 & \\
\hline No & $73,58,52$ & & $60,60,60$ & & 0.880 \\
\hline Yes & $60,34,30$ & & $38,38,19$ & & 0.628 \\
\hline LNR & & $0.041 *$ & & 0.166 & \\
\hline$\leq 0.2$ & $69,56,51$ & & $58,58,58$ & & 0.985 \\
\hline$>0.2$ & $60,25,19$ & & $25,25,0$ & & 0.501 \\
\hline LNR & & $0.004 *$ & & 0.104 & \\
\hline$\leq 0.3$ & $71,54,50$ & & $61,61,50$ & & 0.860 \\
\hline$>0.3$ & $50,17,8$ & & $0,0,0$ & & 0.460 \\
\hline Number of lymph nodes & & 0.086 & & 0.523 & \\
\hline$\leq 6$ & $20,20,20$ & & $39,39,39$ & & 0.252 \\
\hline$>6$ & $70,47,41$ & & $57,57,38$ & & 0.785 \\
\hline Number of lymph nodes & & 0.411 & & 0.639 & \\
\hline$\leq 15$ & $59,40,34$ & & $41,41,41$ & & 0.801 \\
\hline$>15$ & $70,48,43$ & & $60,60,40$ & & 0.914 \\
\hline
\end{tabular}

RFS $=$ Recurrence-Free survival. Data reported as Kaplan-Meier estimated rates, with p-values from log-rank tests. *Significant at $\mathrm{p}<0.05$.

Table 8: Long term survival outcomes.

\begin{tabular}{|lllll|}
\hline \multicolumn{1}{|c|}{} & \multicolumn{1}{c|}{ Years post-surgery } & p-value \\
\hline Overall survival & 1 year & 3 years & years & 0.943 \\
\hline PD & & & $45 \%(12)$ & \\
\hline Pancreas sparing duodenectomy & $76 \%(43)$ & $53 \%(22)$ & $40 \%{ }^{40}$ & 0.781 \\
\hline Disease specific survival & & $47 \%(6)$ & $61 \%(12)$ \\
\hline PD & $94 \%(43)$ & $71 \%(22)$ & $68 \%{ }^{40}$ \\
\hline Pancreas sparing duodenectomy & $93 \%(11)$ & $68 \%(6)$ & & 0.695 \\
\hline Recurrence-free survival & & & $36 \%(9)$ & \\
\hline PD & $65 \%(37)$ & $44 \%(19)$ & $37 \%{ }^{40}$ & \\
\hline Pancreas sparing duodenectomy & $51 \%(8)$ & $44 \%(6)$ & \\
\hline
\end{tabular}

Data reported as Kaplan-Meier estimates of survival and numbers at risk. P-values are from Log-Rank tests, using all available followup.
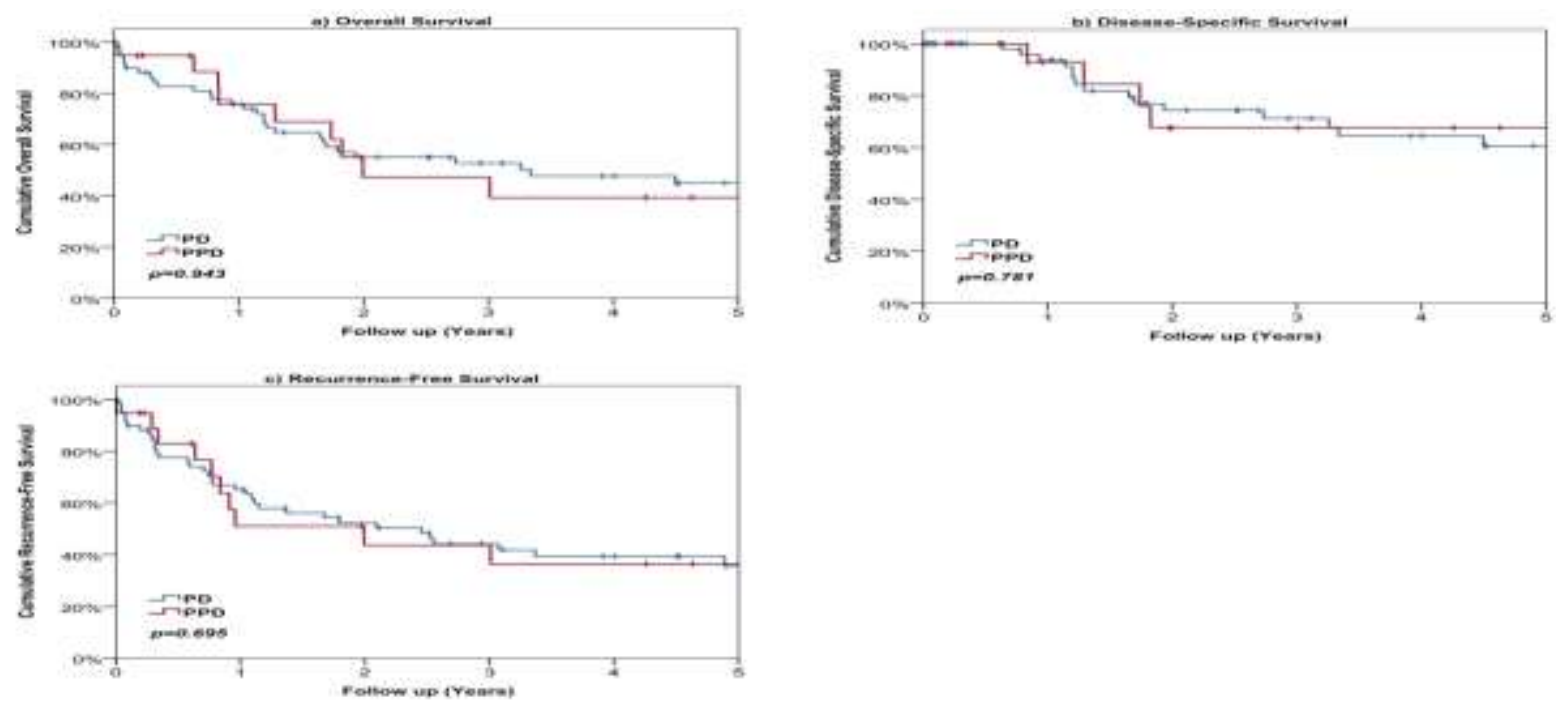

Figure 3: Survival outcomes: comparing 5 year overall, disease specific and recurrence free survival between PSD and PD groups. 


\section{DISCUSSION}

Duodenal cancer is rare, but in the absence of distant metastases, surgical resection offers the potential for long-term survival and cure. ${ }^{9}$ The surgical management of duodenal pathology is challenging because of its retroperitoneal position and shared blood supply with the pancreas, and PD is the preferred option regardless of tumor site. ${ }^{10,11}$ Even though the mortality is decreasing with PD resection, the morbidity is still significantly high. ${ }^{6}$

Our study suggest that pancreas-sparing partial duodenectomy, which avoids pancreatic anastomosis and thus pancreatic leak, is a feasible alternative for tumours not involving the ampulla, with comparable long-term results. ${ }^{5,12}$ Duodenal and periampullary lesions comparable due their anatomical location, shared blood supply, similar clinical presentation and association with hereditary syndromes. ${ }^{13}$ Several series have demonstrated no survival difference between periampullary and duodenal malignancies. ${ }^{5}$

Previous data on PSD have been limited to case reports or small cases series and there were no exhaustive data regarding the relationship between survival and type of surgical resection for duodenal carcinoma. ${ }^{6}$ There were no study comparing the lymph node yield and their role in long-term survival in the management of duodenal carcinoma. This is the first larger study with 19 PSD for duodenal adenocarcinoma and compares the long-term outcomes of PSD and PD for duodenal adenocarcinoma. There are few larger studies describing PSD for duodenal carcinoma. Maher et al and Spalding etal showed median survival of 18.5 months and 56 months after PSD for adenocarcinoma, while Sohn et al showed 1,2,5 years survival of $76,63,0 \% .^{5,6,14}$

The morbidity rates are reported as similar after PD and PSD for duodenal carcinoma. ${ }^{15}$ However some authors reported higher morbidity associated with pancreas sparing duodenal resection than PD, although not significant. ${ }^{16,17}$ Pancreatic fistula, bleeding, abscess and delayed gastric emptying are some reported complications after duodenal resection either with PD or PSD ${ }^{7}$ However pancreatic leak was reported to present in $33-66 \%$ of cases after PD and none with PSD. ${ }^{15,16}$ Our results showed $33 \%$ pancreatic fistula rate in the PD group, this is due to soft nature of the pancreas and smaller pancreatic duct associated with duodenal carcinoma compared with pancreatic tumours. ${ }^{18}$ Spalding et al reported anastomotic leak (7\%), bleeding and delayed gastric emptying as complications after PSD. ${ }^{6}$ Maher et al showed $8 \%$ anastomotic leak, but on Sohn et al reported $30 \%$ anastomotic leak. ${ }^{5,14}$ They have also reported no pancreatic complications and less DGE occurred in the PSD group. ${ }^{6}$ With advanced surgical techniques in highly specialised units the operative mortality of PD has been reported as $2-4 \%$, while review on pancreas sparing resection has shown the mortality rate of $2 \% .^{6}$ The high mortality observed after PD in this series may be attributed the long time period of the study, which dates back to 1993. 30-day mortality after pancreaticoduodenectomy in our unit in a contemporary series was $2.5 \% .^{20}$

Even though PSD is an alternative option for PD in duodenal tumour resection; this can be associated with limited dissection, resection and low lymph node yield. Overman et al suggested poor outcome in small bowel adenocarcinoma associated with lymph node involvement. $^{21} 5$ years survival after surgery for duodenal carcinoma has been reported as $0 \%$ and $68 \%$ with and without lymph node involvement. ${ }^{22,23}$ However some authors found lymph node involvement did not show any significant difference in survival ${ }^{24,25}$ Thus, there is controversy regarding the lymph node status and survival in periampullary/duodenal carcinomas. Memorial SloanKettering Cancer Centre showed that nodal metastases, regardless of their location, do not have an impact on survival. Only resectability and the presence of non-nodal metastases predicts outcome. ${ }^{26}$ Bakeen et al and Sarela et al suggested that lymph node invasion is a very important indicator for long term survival, more important than tumour size, or local invasion. ${ }^{11,27}$

Overman et al found that survival rates are related to total number of lymph nodes removed and number of positive lymph nodes. ${ }^{21}$ Similar conclusions were obtained from several studies. In our series lymph node involvement showed poor disease specific survival in the PD group, but when comparing with PSD group there no difference in overall, disease specific and recurrence free survival.

The total number of lymph nodes to be removed in periampullary and pancreatic cancer has not yet been agreed. College of American Pathologist suggested 15 lymph nodes to be removed in exocrine pancreatic tumours. ${ }^{28,29}$ The minimum lymph node yield associated with an improved long-term survival after resection of periampullary carcinoma is in the range $10-16$, but there is limited available data specifically relating to duodenal adenocarcinoma. ${ }^{28,30,31}$ In this study, we evaluated cut-off values of 6 (median lymph node yield in PSD group) and 15 (CAP recommendation). Although there was a trend in favour of improved survival after PD in patients with a lymph node yield greater than six (Table 5-7), this did not reach statistical significance, possibly due to a type II error. Our data has shown that although PSD is associated with a reduced lymph node yield compare to $\mathrm{PD}$, this did not significantly impact on long-term survival. We did calculate the lymph node ratio for both PSD and PD patients, but this was not significant on comparison, though high ratio was associated with poor survival as described in the literature. ${ }^{28,32,33}$ 
Lymph node ratio (LNR) has been shown to be an important prognostic factor after resection of pancreatic ductal adenocarcinoma and periampullary carcinomas. ${ }^{32,33}$ Several previously published series compared the LNR of $0.2,0.3$ and 0.4 and found that greater the LNR, the worse the prognosis. ${ }^{28,32}$. We compared the survival for LNR of $>0.2$ and $>0.3$ within and between the groups. There were no patients with LNR of $>0.4$ in our group. Our results showed that LNR of $>0.2$ and $>0.3$ were associated with poor overall and recurrence free survival in the PD group, but this was not significant in the PSD group; this may be due to low statistical power. There was no significant difference in overall, recurrence free and disease specific survival when compared the LNR between PSD and PD groups (Tables 5-7).

Adenocarcinoma of the duodenum is the least common type of periampullary tumour, but the prognosis is generally better than for carcinoma of the pancreas or distal bile duct. ${ }^{34,35}$ Hui-Ping Hsu et al. reported overall 5-year survival rate for periampullary carcinoma was $40.9 \%$ and the actuarial disease-specific 5-year survival rate was $45.7 \%$. ${ }^{36}$ And Katz et al reported 27\% 5-year survival rate for pancreatic adenocarcinoma. ${ }^{37}$

In a previous study of 13 patients who underwent PSD, five-year survival was significantly worse after PSD compared to PD (0\% vs. $69 \%)$, and this was attributed to higher stage tumours in PSD patients. ${ }^{5}$ In our data, the proportion of patients with Stage III-IV disease was similar between groups. There are 2 patients with stage 4 disease in our group who had PD, 1 had small cystic lesion in the ovary which was removed as it was thought as simple cyst and another patient had thick walled cystic lesion in the left lobe of liver, which was thought as cystadenoma. But histologically they were confirmed as metastases from duodenum.

Overman MJ reported no survival benefit from adjuvant chemotherapy following curative resection of duodenal adenocarcinoma. ${ }^{38}$ This was confirmed by Duke University series in 2007, however the same series reported survival benefit with chemoradiotherapy only in the subgroup of patients who had negative resection margin (83\% vs. 53\%), though it was not statistically significant $(\mathrm{p}=0.07){ }^{39}$

Even though we have the largest number of patients who had PSD for duodenal carcinoma, there are limitations due to retrospective nature of the study. Due to long period of inclusion during which advances in chemotherapy during the study period may affect the survival, but the authors do not believe that this would significantly influence our results, since the distribution of both procedures (PD and PSD) over the study period was similar. Multi-centre registry on management of duodenal carcinoma would help to capture accurate data in future.

\section{CONCLUSION}

We conclude that PSD is a feasible alternate option in patients with duodenal cancer. Certainly PD is associated with pancreatic leak, which is associated with significant mortality and this can be avoided with PSD. Despite a higher rate of positive margins, though not statistically significant, and a significantly lower lymph node harvest, similar survival outcomes can be achieved with PSD in patients with duodenal carcinoma not involving D2.

Funding: No funding sources

Conflict of interest: None declared

Ethical approval: The study was approved by the Local audit committee

\section{ACKNOWLEDGEMENTS}

Authors would like to thank, MP and RS to initiate the study; MP, MSK, SP collected the data, MP and JH analysed the data; MP and RS were responsible for the manuscript preparation and submission; all co-authors actively contributed to the article drafting and approved the final manuscript.

\section{REFERENCES}

1. Gonzalez GD, Evans EC. Primary adenocarcinoma of the duodenum. Am Surg. 1987;53(3):174-9.

2. Bilimoria KY, Bentrem DJ, Wayne JD, Ko CY, Bennett CL, Talamonti MS. Small bowel cancer in the United States: changes in epidemiology, treatment, and survival over the last 20 years. Annals of surgery. 2009;249(1):63-71.

3. Egberts JH, Scharrer ML, Hinz S, Schafmayer C, Klomp HJ, Faendrich F, Tepel J. Small bowel cancer: single-centre results over a period of 12 years. Hepatogastroenterology. 2007;54(73):129-34.

4. Hu JX, Miao XY, Zhong DW, Dai WD, Liu W, Hu W. Surgical treatment of primary duodenal adenocarcinoma. 2006;53(72):858-62.

5. Sohn TA, Lillemoe KD, Cameron JL, Pitt HA, Kaufman HS, Hruban RH, Yeo CJ. Adenocarcinoma of the duodenum: factors influencing long-term survival. Journal of gastrointestinal surgery. Official j Society Surg Aliment Tract. 1998;2(1):79-87.

6. Spalding DR, Isla AM, Thompson JN, Williamson RC. Pancreas-sparing distal duodenectomy for infrapapillary neoplasms. Ann R Coll Surg Engl. 2007;89(2):130-5.

7. Sista F, Santis GD, Giuliani A, Cecilia EM, Piccione F, Lancione L, Leardi S, Amicucci G. Adenocarcinoma of the third duodenal portion: Case report and review of literature. World J gastro surg. 2012;4(1):23-6.

8. Dindo D, Demartines N, Clavien PA. Classification of surgical complications: a new proposal with 
evaluation in a cohort of 6336 patients and results of a survey. Annals of surgery. 2004;240(2):205-13.

9. Futorian ES, Zabaznyi NP, Kozhevnikova AD. (Primary cancer of the duodenum). Vestnik khirurgii imeni I I Grekova. 1978;120(6):24-8.

10. Bal A, Joshi K, Vaiphei K, Wig JD. Primary duodenal neoplasms: a retrospective clinicopathological analysis. World J Gastro. 2007;13(7):1108-11.

11. Bakaeen FG MM, Sarr MG, Thompson GB, Farnell MB, Nagorney DM. What prognostic factors are important in duodenal adenocarcinoma? Archives of surgery. 2000;135:635-41.

12. Hung FC, Kuo CM, Chuah SK, Kuo CH, Chen YS, Lu SN, Chang Chien CS. Clinical analysis of primary duodenal adenocarcinoma: an 11-year experience. J Gastro Hepato. 2007;22(5):724-8.

13. Taylor A, Sohn CJ. Pancreatic and periampullary carcinoma (Nonendocrine). Shackelford's Surgery of the Alimentary Tract. 1996;3(5):5001-26.

14. Maher MM, Yeo CJ, Lillemoe KD, Roberts JR, Cameron JL. Pancreas-sparing duodenectomy for infra-ampullary duodenal pathology. Am J Surg. 1996;171(1):62-7.

15. Kaklamanos IG, Bathe OF, Franceschi D, Camarda C, Levi J, Livingstone AS. Extent of resection in the management of duodenal adenocarcinoma. Am J Surg. 2000;179(1):37-41.

16. Chung RS, Church JM, vanStolk R. Pancreassparing duodenectomy: indications, surgical technique, and results. Surgery. 1995;117(3):254-9.

17. Castro SM, Van CH, Rutten JP, Dejong CH, Goor $\mathrm{H}$, Busch OR, Gouma DJ. Pancreas-preserving total duodenectomy versus standard pancreatoduodenectomy for patients with familial adenomatous polyposis and polyps in the duodenum. British J Surg. 2008;95(11):1380-6.

18. Yeo CJ, Cameron JL, Sohn TA, Lillemoe KD, Pitt HA, Talamini MA, Hruban RH, Ord SE, Sauter PK, Coleman J, Zahurak ML, Grochow LB, Abrams RA. Six hundred fifty consecutive pancreaticoduodenectomies in the 1990s: pathology, complications, and outcomes. Annals of surgery. 1997;226(3):248-57.

19. Ammori BJ, Jenkins BL, Lim PC, Prasad KR, Pollard SG, Lodge JP. Surgical strategy for cystic diseases of the liver in a western hepatobiliary center. World J Surg 2002;26(4):462-9.

20. Sutcliffe RP, Hamoui M, Isaac J, Marudanayagam R, Mirza DF, Muiesan P, Roberts JK. Implementation of an enhanced recovery pathway after pancreaticoduodenectomy in patients with low drain fluid amylase. World J Surgery. 2015;39(8):2023-30.

21. Overman MJ, Hu CY, Wolff RA, Chang GJ. Prognostic value of lymph node evaluation in small bowel adenocarcinoma: analysis of the surveillance, epidemiology, and end results database. Cancer. 2010;116(23):5374-82.
22. Lang H, Nadalin S, Raab R, Jahne J. (Results of surgical therapy of primary adenocarcinoma of the duodenum). Der Chirurg; Zeitschriftfur alle Gebiete der operativen Medizen.1999;70(5):571-7.

23. Vuilleumier H, Cuttat JF, Blum AL, Chapuis G. (Adenocarcinoma of the duodenum. Contribution to the study of a rare pathology). Helvetica Chirurgica Acta. 1994;60(4):557-67.

24. Cheng XD, Xu ZY, Huang L, Yang LT, Wang B, Zhou YM, Yu PF, Yu QM. A modified pancreaticojejunostomy: pancreaticojejunostomy. Hepatogastroenterology. 2011;59(113):289-91.

25. Bucher P, Gervaz P, Morel P. Long-term results of radical resection for locally advanced duodenal adenocarcinoma.

Hepatogastroenterology. 2005;52(66):1727-9.

26. Rose DM, Klimstra DS, Brennan MF. Primary duodenal adenocarcinoma: a ten-year experience with 79 patients. J Am College Surg. 1996:183;8996.

27. Sarela AI, Brennan MF, Karpeh MS, Klimstra D, Conlon KC. Adenocarcinoma of the duodenum: importance of accurate lymph node staging and similarity in outcome to gastric cancer. Annals Surg Oncology. 2004;11(4):380-6.

28. Falconi M, Crippa S, Dominguez I, Barugola G, Capelli P, Marcucci S, Beghelli S, Scarpa A, Bassi C, Pederzoli P. Prognostic relevance of lymph node ratio and number of resected nodes after curative resection of ampulla of Vater carcinoma. Annals Surg Onco. 2008;15(11):3178-86.

29. Washington KBJ, Branton P, Burgart LJ, Carter DK, Fitzgibbons P, Frankel WL, Jessup J, Kakar S, Minsky B, Nakhleh R, Compton. Protocol for the examination of specimens from patients with carcinoma of the exocrine pancreas. College of American Pathologists. June 2012.

30. Slidell MB, Chang DC, Cameron JL, Wolfgang C, Herman JM, Schulick RD, Choti MA, Pawlik TM. Impact of total lymph node count and lymph node ratio on staging and survival after pancreatectomy for pancreatic adenocarcinoma: a large, populationbased analysis. Annals Surg Oncology. 2008;15(1):165-74.

31. Gutierrez JC, Koniaris LG. How many lymph nodes properly stage a periampullary malignancy? J Gastro Surg. 2008;12(1):77-85.

32. Bhatti IPO, Awan AK, Semeraro D, Larvin M, Hall RI. Lymph node ratio versus number of affected lymph nodes as predictors of survival for resected pancreatic adenocarcinoma. World J Surg. 2010;34(4):768-75.

33. Hurtuk MG, Hughes C, Shoup M, Aranha GV. Does lymph node ratio impact survival in resected periampullary malignancies? American journal of surgery 2009;197(3):348-52.

34. Michelassi F, Erroi F, Dawson PJ, Pietrabissa A, Noda S, Handcock M, Block GE. Experience with 647 consecutive tumors of the duodenum, ampulla, 
head of the pancreas, and distal common bile duct. Annals Surg. 1989;210(4): 544-54.

35. Scott-Coombes DM, Williamson RC. Surgical treatment of primary duodenal carcinoma: a personal series. British J Surgery. 1994;81(10):1472-4.

36. Hsu HP, Yang TM, Hsieh YH, Shan YS, Lin PW. Predictors for patterns of failure after pancreaticoduodenectomy in ampullary cancer. Annals Surg Onco. 2007;14(1):50-60.

37. Katz MH, Wang H, Fleming JB, Sun CC, Hwang RF, Wolff RA, Varadhachary G, Abbruzzese JL, Crane CH, Krishnan S, Vauthey JN, Abdalla EK, Lee JE, Pisters PW, Evans DB. Long-term survival after multidisciplinary management of resected pancreatic adenocarcinoma. Annals Surg Onco. 2009;16(4):836-47.
38. Overman MJ. Recent advances in the management of adenocarcinoma of the small intestine. Gastrointest Cancer Res. 2009;3(3):90-6.

39. Kelsey CR, Nelson JW, Willett CG, Chino JP, Clough RW, Bendell JC, Tyler DS, Hurwitz HI, Morse MA, Clary BM, Pappas TN, Czito BG. Duodenal adenocarcinoma: patterns of failure after resection and the role of chemoradiotherapy. Int $\mathbf{J}$ Radiat Oncol Biol Phys. 2007;69(5):1436-41.

40. Koneru B, Tzakis AG, Bowman J, Cassavilla A, Zajko AB, Starzl TE. Postoperative surgical complications. Gastroentero Clinics North Am. 1988;17(1):71-91.

Cite this article as: Pitchaimuthu M, Khan MS, Pearson S, Coldham C, Hodson J, Marudanayagam $\mathrm{R}$, et al. Pancreas sparing duodenectomy versus pancreaticodudoenectomy for duodenal carcinoma: a comparison study. Int Surg J 2016;3:1051-60. 